\title{
A Novel and Multivalent Role of Pax6 in Cerebellar Development
}

\author{
기 Joanna Yeung, Tㅜㅇomas J. Ha, Douglas J. Swanson, and DD Dan Goldowitz \\ Department of Medical Genetics, Centre for Molecular Medicine and Therapeutics, Child and Family Research Institute, University of British Columbia, \\ Vancouver, British Columbia V5Z 4H4, Canada
}

Pax6 is a prominent gene in brain development. The deletion of Pax6 results in devastated development of eye, olfactory bulb, and cortex. However, it has been reported that the Pax6-null Sey cerebellum only has minor defects involving granule cells despite Pax6 being expressed throughout cerebellar development. The present work has uncovered a requirement of Pax6 in the development of all rhombic lip (RL) lineages. A significant downregulation of Tbr1 and Tbr2 expression is found in the Sey cerebellum, these are cell-specific markers of cerebellar nuclear (CN) neurons and unipolar brush cells (UBCs), respectively. The examination of Tbr1 and Lmxla immunolabeling and Nissl staining confirmed the loss of CN neurons from the Sey cerebellum. CN neuron progenitors are produced in the mutant but there is an enhanced death of these neurons as shown by increased presence of caspase-3-positive cells. These data indicate that Pax 6 regulates the survival of $\mathrm{CN}$ neuron progenitors. Furthermore, the analysis of experimental mouse chimeras suggests a cell-extrinsic role of Pax6 in $\mathrm{CN}$ neuron survival. For UBCs, using Tbr2 immunolabeling, these cells are significantly reduced in the Sey cerebellum. The loss of UBCs in the mutant is due partly to cell death in the RL and also to the reduced production of progenitors from the RL. These results demonstrate a critical role for Pax6 in regulating the generation and survival of UBCs. This and previous work from our laboratory demonstrate a seminal role of Pax6 in the development of all cerebellar glutamatergic neurons.

Key words: Atoh1; Pax6; rhombic lips; Tbr1 and cerebellar nuclear neurons; Tbr2 and unipolar brush cells

\section{Significance Statement}

Pax6 is a key molecule in development. Pax6 is best known as the master control gene in eye development with mutations causing aniridia in humans. Pax6 also plays important developmental roles in the cortex and olfactory bulb. During cerebellar development, Pax6 is robustly expressed in the germinal zone of all glutamatergic neurons [cerebellar nuclear (CN) neurons, granule cells, and unipolar brush cells (UBCs)]. Past work has not found abnormalities in the CN and UBC populations. Our study reveals that the Pax6-null mutation dramatically affects these cells and identifies Pax6 as a key regulator of cell survival in CN neurons and of cell production in UBCs. The present study shows how Pax6 is key to the development of glutamatergic cells in the cerebellum.

\section{Introduction}

The paired box transcription factor Pax6 has been shown to have a fundamental role in the development of several CNS structures in which it is expressed during development. The absence of Pax6

\footnotetext{
Received Nov. 30, 2015; revised July 8, 2016; accepted July 12, 2016.

Author contributions: J.Y. and D.G. designed research; J.Y., D.J.S., and D.G. performed research; T.H. contributed unpublished reagents/analytic tools; J.Y., T.H., D.J.S., and D.G. analyzed data; J.Y. and D.G. wrote the paper.

This work was supported by the Natural Sciences and Engineering Research Council of Canada, NeuroDevNet, Canadian Institutes of Health Research, and Centre for Molecular Medicine and Therapeutics/Child and Family Research Institute start-up funds. We thank Thomas Jessell for generously providing us with the IRX1 antibody. We thank Shiqi Jia, Thomas Müller, and Carmen Birchmeier for generously providing us with the INSM1 antibody. We thank Matthew Larouche for his valuable advice on the design of experiments. We also thank Kunho Choi, Janice Yoo, Derek Rains, and Fernando Lucero Villegas for their expert technical assistance.

The authors declare no competing financial interests.

Correspondence should be addressed to Dan Goldowitz, Centre for Molecular Medicine and Therapeutics, Child and Family Research Institute, 950 West 28th Avenue, Vancouver, BC V5Z4H4, Canada. E-mail: dang@cmmt.ubc.ca. DOI:10.1523/JNEUROSCI.4385-15.2016

Copyright $\odot 2016$ the authors $\quad 0270-6474 / 16 / 369057-13 \$ 15.00 / 0$
}

results in the loss of progenitor and cell-type mis-specifications (Ericson et al., 1997; Toresson et al., 2000; Quinn et al., 2007). One brain region that has early and compartmental expression of Pax6, but has escaped the detection of a seminal role in development, is the cerebellum. However, in our recent work with Pax6, we have identified a transition of molecular identity in the Pax6null cerebellum (Yeung et al., 2014), which prompted a reexamination of Pax6 and early development of the cerebellum.

In the cerebellum, Pax6 is expressed early on in the cells of the rhombic lip (RL) that give rise to neurons of the glutamatergic lineages, including the cerebellar nuclear $(\mathrm{CN})$ neurons, granule cells (GCs), and unipolar brush cells (UBCs). Compared with the crucial control exerted by Pax6 in other CNS regions, Pax6 only seems to play a modulatory later-developmental role in cerebellar development. For example, the loss of Pax6 has been reported to result in the aberrant organization of the external GC layer and foliation in the cerebellum (Engelkamp et al., 1999; Swanson et 
al., 2005; Swanson and Goldowitz, 2011). The influence of Pax6 on the CN neurons and UBCs, however, has not been reported.

We previously assessed the whole-genome transcriptomic profile of the cerebellum in the absence of Pax6 during embryonic development (Ha et al., 2012). Comparison of the transcriptome profiles from Pax6-null (Sey) mutant and wild-type cerebella revealed a significant decrease in the expression of Tbr1 and Tbr2 (Eomes) in the Sey cerebellum (Ha et al., 2012, 2015), transcription factors important for the development of CN neurons and UBCs, respectively (Englund et al., 2006; Fink et al., 2006). These data also suggested that a closer examination of cells in the glutamatergic lineage should be explored in the Pax6-null mutant cerebellum.

Here we report two dramatic phenotypes in the Pax6 knock-out mouse cerebellum: loss of glutamatergic $\mathrm{CN}$ neurons and UBCs. The loss of these cells seems largely attributable to enhanced cell death in RL-derived CN progenitors and enhanced cell death and decreased neurogenesis in the UBCs. Our data reveal a previously unreported requirement for Pax6 in the survival and generation of glutamatergic CN neurons and UBCs in the developing cerebellum. These findings support a revised view of the molecular program that underpins cerebellar development.

\section{Materials and Methods}

Mouse strains and husbandry. The Pax6 mutant strain Pax6 ${ }^{\text {Sey }}$ (originally obtained from Robert Grainger and Marilyn Fisher, University of Virginia) was bred as heterozygous pairs, phenotyped for eye sizes and presence of cataracts, and genotyped as previously described (Swanson et al., 2005). Experimental Pax $6^{\text {Sey/Sey }}$ embryos were generated by intercrossing $\mathrm{Pax}^{\mathrm{Sey} /+}$ mice.

The Atoh1-lacZ reporter strain Atoh $1^{\beta-G a l}$ (obtained from Huda Zoghbi, Baylor College of Medicine) was genotyped by PCR according to the protocol previously described (Jensen et al., 2002). Experimental, double-heterozygous $\mathrm{Pax}_{6}^{\mathrm{Sey} /+} ;$ Atoh $1^{\beta-G a l /+}$ embryos were generated from the matings between heterozygous $\operatorname{Pax}^{\mathrm{Sey} /+}$ and Atoh $1^{\beta-G a l /+}$ mice.

The morning that a vaginal plug was detected was designated as embryonic day (E) 0.5. All studies were conducted according to the protocols approved by Institutional Animal Care and Use Committee and Canadian Council on Animal Care at the University of Tennessee Health Science Center and the University of British Columbia.

Experimental mouse chimeras. Experimental mouse chimeras were generated as previously described (Goldowitz and Mullen, 1982; Goldowitz, 1989). The mutant component of the chimera was generated by a mating of heterozygous Sey mutants $\left(\mathrm{Pax}^{\mathrm{Sey} /+}\right)$, which yielded $\mathrm{Pax}^{+/+}$, $\mathrm{Paxb}^{\text {Sey/+ }}$, and Pax6 ${ }^{\text {Sey/Sey }}$ embryos. To mark the wild-type cells of experimental chimeras, we used FVB-GFP mice [FVB.Cg-Tg(CAGEGFP)B5Nagy/J; Jackson Laboratory; stock number: 003516]. Four-toeight-cell embryos from $\mathrm{Pax}^{\mathrm{Sey} /+}$ matings $\left(\mathrm{Pax6}^{+/+}, \mathrm{Pax}^{\mathrm{Sey} /+}\right.$, or $\mathrm{Pax6}^{\mathrm{Sey} / \mathrm{Sey}}$ ) were cultured together with embryos from wild-type (GFP) matings overnight. After successful fusion, blastocyts were transplanted into the uterine horn of pseudopregnant host ICR females. Chimera embryos were collected on E18.5, and tail biopsies were taken for genotyping of the $\mathrm{Pax}^{\mathrm{Sey}}$ component using a mutagenically separated PCR technique as previously described (Swanson et al., 2005). Tissue was processed and sectioned as described below.

Percentage chimerism was estimated from expression of GFP fluorescence (wild-type cells) in various brain regions outside the cerebellum. For each chimeric brain, GFP expression from 13 to 16 coronal sections were analyzed and averaged.

$\mathrm{CN}$ neuron phenotype was assessed by counting Tbr $1^{+}$cells from 13 to 16 coronal sections across the full cerebellum, right and left sides inclusive. We determined the number of $\mathrm{Tbr}^{+} \mathrm{CN}$ neurons from the cerebellum of two wild-type $\mathrm{Pax}^{+/+}<->+/+$chimera, three heterozygous $\mathrm{Pax6}^{\text {Sey/+ }}<->+1+$ chimera, three mutant $\mathrm{Pax6}^{\text {Sey/Sey }}<->+1+$ chimeras, and four mutant $\mathrm{Pax}_{6}{ }^{\mathrm{Sey} / \mathrm{Sey}}$ embryos. The total number of Tbr $1^{+}$ $\mathrm{CN}$ neurons in each cerebellum was calculated, and averages were taken for all groups of embryos. For the mutant chimeric cerebellum, the expected number of $\mathrm{Tbr}^{+}$cells was predicted based on the percentage chimerism (of the wild-type and mutant genotypes) multiplied by the average cell counts from wild-type and mutant cerebellum (see text). Statistical significance between the expected and observed $\mathrm{Tbr} 1^{+}$cells in the mutant chimeric cerebellum was determined by $\chi^{2}$ test.

Tissue preparation and histology. All embryos were collected at every age from E11.5 to E18.5. Embryos harvested between E10.5 and E15.5 were fixed by immersion in $4 \%$ paraformaldehyde in $0.1 \mathrm{M}$ phosphate buffer (PB), pH 7.4, for $1 \mathrm{~h}$ at $4^{\circ} \mathrm{C}$. Embryos harvested at E16.5 or later were perfused with $4 \%$ paraformaldehyde in $0.1 \mathrm{M} \mathrm{PB}$. The brain tissues were isolated and further fixed in $4 \%$ paraformaldehyde in $0.1 \mathrm{M} \mathrm{PB}$ for $1 \mathrm{~h}$ at room temperature. Fixed tissues were rinsed with PBS, followed by cryoprotection with $30 \%$ sucrose/PBS overnight at $4^{\circ} \mathrm{C}$ before embedding in optimal cutting temperature compound. Tissues were sectioned at $12 \mu \mathrm{M}$ for immunohistochemistry and cryosections were mounted on Superfrost slides (Thermo Fisher Scientific), air dried at room temperature, and stored at $-80^{\circ} \mathrm{C}$ until used. In all cases, observations were based on $\geq 3$ embryos per genotype per experiment.

Immunohistochemistry. Tissue sections were rehydrated to PBS. For bright-field immunohistochemistry, endogenous peroxidase activity was inhibited by treating the sections with $1 \% \mathrm{H}_{2} \mathrm{O}_{2}$ in PBS followed by PBS-T (0.1 M PBS/0.1\% Triton X-100) rinse. Sections were incubated at room temperature for 20 min with blocking solution (1\% BSA and 5\% normal serum in PBS-T) and subsequently incubated at room temperature overnight with primary antibodies in a humid chamber. Following PBS-T washes, the sections were incubated with biotinylated secondary antibodies (at 1:200; Vector Laboratories) and processed for PAP immunohistochemistry using the $\mathrm{ABC}$ Kit (Vector Laboratories) according to the manufacturer's protocol. Slides were dehydrated and coverslips were applied. For immunofluorescence, secondary antibodies labeled with fluorochrome were used to recognize the primary antibodies. The slides were coverslipped with FluorSave (Calbiochem, 345789). Primary antibodies used were as follows: chicken anti- $\beta$-gal (1:10,000; Abcam, Ab9361, RRID:AB_307210), rat anti-BrdU (1:300; Abcam, Ab6326, RRID:AB_305426), rabbit-anti-active caspase-3 (1:500; Abcam, Ab13 847, RRID:AB_443014), rabbit anti-LMX-1 (1:2000; Millipore, AB10533, RRID:AB_10805970), guinea pig anti-INSM1 (1:1000; a gift from Shiqi Jia, Max-Delbrück-Center for Molecular Medicine); rabbit anti-IRX3 (1:8000; a gift from Tom Jessell, Columbia University), rabbit anti-PAX6 (1:200; Covance, PRB-278P, RRID:AB_291612), rabbit anti-TBR1 (1: 800; Abcam, Ab31940, RRID:AB_2200219), rabbit-anti-TBR2 (1:800; Millipore, AB2283, RRID:AB_10806889).

Cell counts and BrdU analysis. We estimated the numbers of CN neurons and UBCs by counting cells positive for the appropriate cell marker (Tbr1 for CN neurons, Tbr2 for UBCs, and Lmxla for both). Every 10th section across the whole E11.5-E16.5 cerebellum and the half E17.5 and E18.5 cerebellum were counted. The assessment of cell death in CN neuron progenitors was determined by counting anti-caspase-3-positive cells in the nuclear transitory zone (NTZ), subpial stream, and external germinal layer (EGL) of E12.5-E18.5 cerebella. The assessment of cell death in UBCs was determined by counting anti-caspase-3-positive cells in the RL (and immediately adjacent area) of E15.5-E18.5 cerebella.

To examine cell proliferation at the RL during UBC neurogenesis, timed pregnant females were injected intraperitoneally with BrdU (Sigma-Aldrich, B5002; $50 \mu \mathrm{g} / \mathrm{g}$ of body weight) $1 \mathrm{~h}$ before the collection of embryos. To quantify the number of proliferating cells in the cerebellar $\mathrm{RL}, \mathrm{BrdU}^{+}$cells were counted in every 10th section across the whole E16.5 cerebellar RL.

To test the possibility of cell-fate change, cells produced during the period of $\mathrm{CN}$ neuron genesis (E10.5 and E11.5) were labeled with BrdU, and BrdU-labeled cells were analyzed with immunohistochemistry at E15.5. Timed pregnant females were injected intraperitoneally with $\mathrm{BrdU}$ (50 $\mu \mathrm{g} / \mathrm{g}$ of body weight) on E10.5 and E11.5, then embryos were collected on E15.5.

In all cases, observations were based on $\geq 3$ cerebella per genotype. Statistical significance between wild-type and mutant was determined by two-tailed $t$ test. 

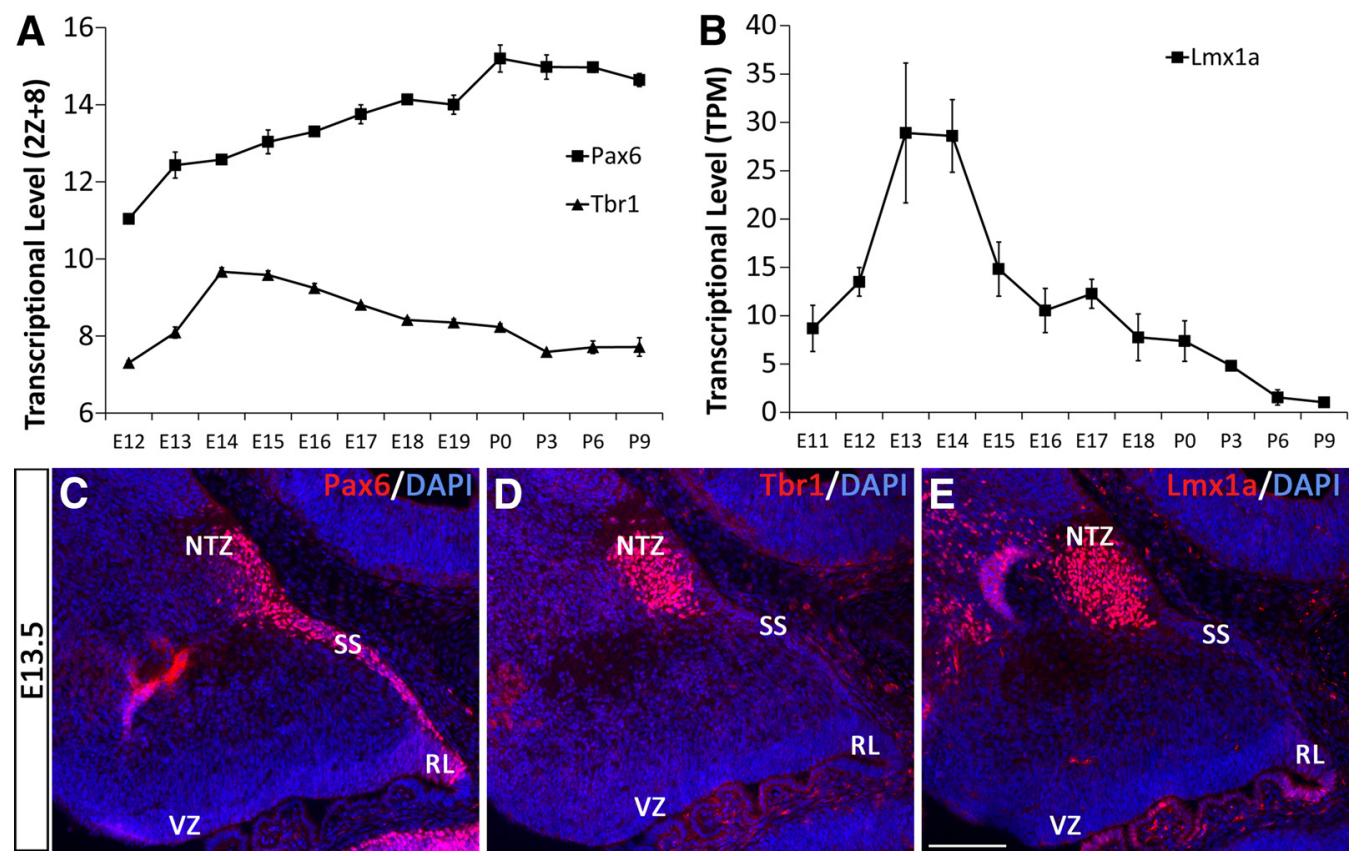

Figure 1. Transcription factors Pax6, Tbr1, and Lmx1a are expressed in the progenitors of $\mathrm{CN}$ neurons during cerebellar development. $A$, The whole-cerebellum transcription profile of Pax6 and Tbr1 during cerebellar development based upon CbGRiTS data. $y$-axis $\log _{2}$ transformed and followed by a $2 Z+8 Z$-score stabilized intensity value for microarray dataset. $\boldsymbol{B}$, The cerebellum transcription profile of $L m x 1 a$ during cerebellar development based upon RIKEN FANTOM5 data. The $y$-axis shows expression level in tags per million (TPM). C, In the E13.5 cerebellum, immunohistochemistry reveals that Pax6 is expressed in the cells of the subpial stream, which houses newly generated CN neuron progenitors. D, E, Once the progenitors enter the NTZ, Pax6 is rapidly downregulated and now these CN neuron progenitors express Tbr1 (D) and Lmx1a (E). SS, Subpial stream. Error bars represent SE. Scale bars, $100 \mu \mathrm{m}$.

Microscopy. Analysis and photomicroscopy was performed with a Zeiss Axiovert 200M microscope with the Axiocam/Axiovision hardware-software components (Carl Zeiss). Confocal microscopy was performed using an Olympus FV500 confocal laser scanning microscope and the Fluoview image capture and analysis software.

\section{Results}

Characterization of the absence of $\mathrm{Tbr}^{+} \mathrm{CN}$ neurons in the Sey cerebellum

Glutamatergic CN neurons are generated from the RL between E10.5 and E12.5 (Machold and Fishell, 2005; Fink et al., 2006). Pax6, Tbr1, and Lmxla are expressed in glutamatergic CN neuron progenitors during development. Our time series cerebellar gene expression microarray dataset (available at cbgrits.org) reveals that during cerebellar development, transcription of Pax6 is expressed throughout the course of embryonic and neonatal stages (Fig. 1A), while the expression of Tbr1 peaks at E14 (Fig. 1A). Transcription levels of Lmxla also peak at E13 and E14 [Fig. $1 B$; RIKEN Center for Life Science Technologies Arner et al., 2015]. Our immunohistochemical analysis shows that Pax6 is expressed in the newly generated $\mathrm{CN}$ neuron progenitors in the $\mathrm{RL}$ and expression persists as these cells migrate tangentially along the subpial stream (Fig. 1C). Between E13 and E15, CN neuron progenitors reach the NTZ, then downregulate Pax6 expression, and in turn initiate Tbrl and Lmxla expression (Fig. $1 D, E)$.

Our Pax6 transcriptome analysis reveals a significant reduction in Tbr 1 transcript in the Sey cerebellum during development (Ha et al., 2012, 2015). At E13.5, there is a 7.89-fold reduction in Tbr1 transcript in the Sey cerebellum (Fig. 2A). Tbr1immunolabeling in the E13.5 wild-type cerebellum detected expression in the $\mathrm{CN}$ neurons that entered the NTZ (Fig. 2B, left). By contrast, this $\mathrm{Tbr}^{+}$population is absent from the NTZ of the Sey cerebellum (Fig. 2B, right). Quantitative analysis of Tbr $1^{+}$ cells in the NTZ indicated an elimination of Tbr $1^{+}$cells from the
E13.5 mutant cerebellum. At E15.5, when Tbr1 ${ }^{+}$cells are localized to the NTZ in wild-type cerebellum, $97.4 \% \mathrm{Tbr}^{+}$cells are missing in the Sey cerebellum (Fig. $2 C$, red arrows; $p=3.7 \times$ $\left.10^{-5}\right)$. By E18.5 in the wild-type cerebellum, the $\mathrm{CN}$ neurons have descended into the cerebellar core and Tbr1 expression is localized to the $\mathrm{CN}$ neurons at the medial level (i.e., fastigial nucleus; Fig. 2D). In contrast, Tbr $1^{+}$cells are not detected in the E18.5 Sey cerebellum (Fig. 2D). At all ages examined, there is no significant difference in the number and location of Tbr $1^{+}$cells in the cerebellum with one copy of Pax6 (i.e., $\mathrm{Pax}^{+/ \text {Sey }}$ ) compared with the wild-type cerebellum (Fig. 2E).

GABAergic CN neurons that arise from ventricular zone (VZ) around the same time migrate radially to enter the NTZ and express Irx3 (Morales and Hatten, 2006). To determine whether GABAergic CN neurons are also affected by the absence of Pax6, we examined Irx $3^{+}$cells in the wild-type and Sey-mutant cerebellum. In the E11.5 wild-type cerebellum, Irx $3^{+}$cells are seen at their origins in the $\mathrm{VZ}$ and migrating through the cerebellar core. By E13.5, the Irx3 ${ }^{+} \mathrm{CN}$ neurons reach the NTZ. By E15.5 the $\mathrm{Irx}^{+}$cells descend into the cerebellar core and are located more laterally than the glutamatergic $\mathrm{Tbr}^{+} \mathrm{CN}$ neurons. At these time points, the expression of Irx3 is indistinguishable between the wild-type and Sey-mutant cerebellum (Fig. 2F). This finding indicates that the production and development of GABAergic CN neurons is not affected by the absence of Pax6.

\section{Reduction of $\mathrm{Lmxla}^{+}$cells in the NTZ of the Sey cerebellum}

We examined Lmxla expression in Sey cerebellum to test whether the effect of the loss of Pax6 is a general elimination of glutamatergic $\mathrm{CN}$ neuron marker expression or is specific to elimination of Tbr1 expression in the CN neurons. $\mathrm{Lmxla}^{+}$cells in the Sey mutant is completely eliminated from the NTZ region at E13.5 (Fig. $3 A$ ) and reduced significantly at E15.5 $\left(p=4.68 \times 10^{-4}\right.$; Fig. $\left.3 B\right)$; similar to the aforementioned loss of Tbr1 expression in the absence of Pax6. 

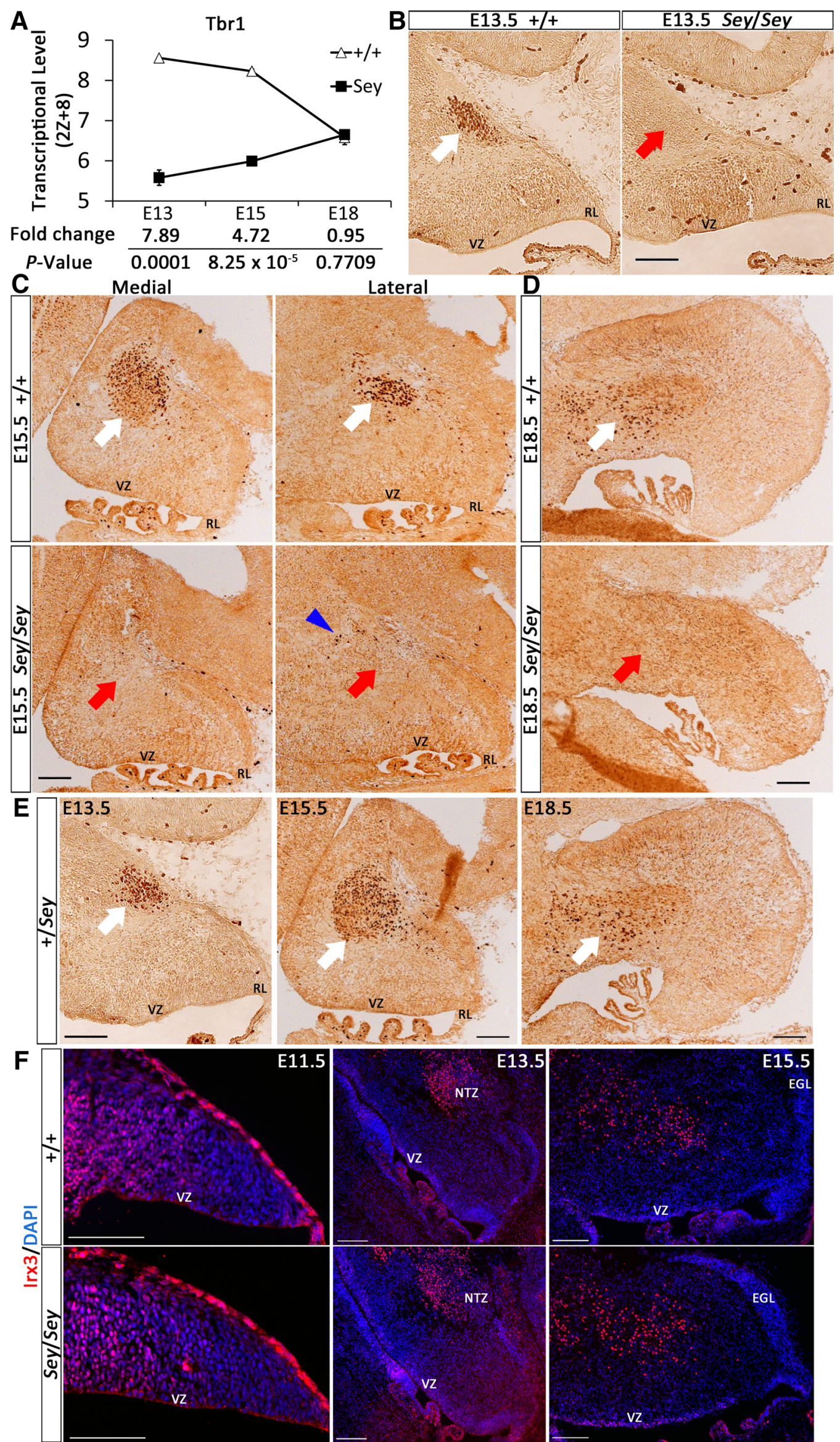


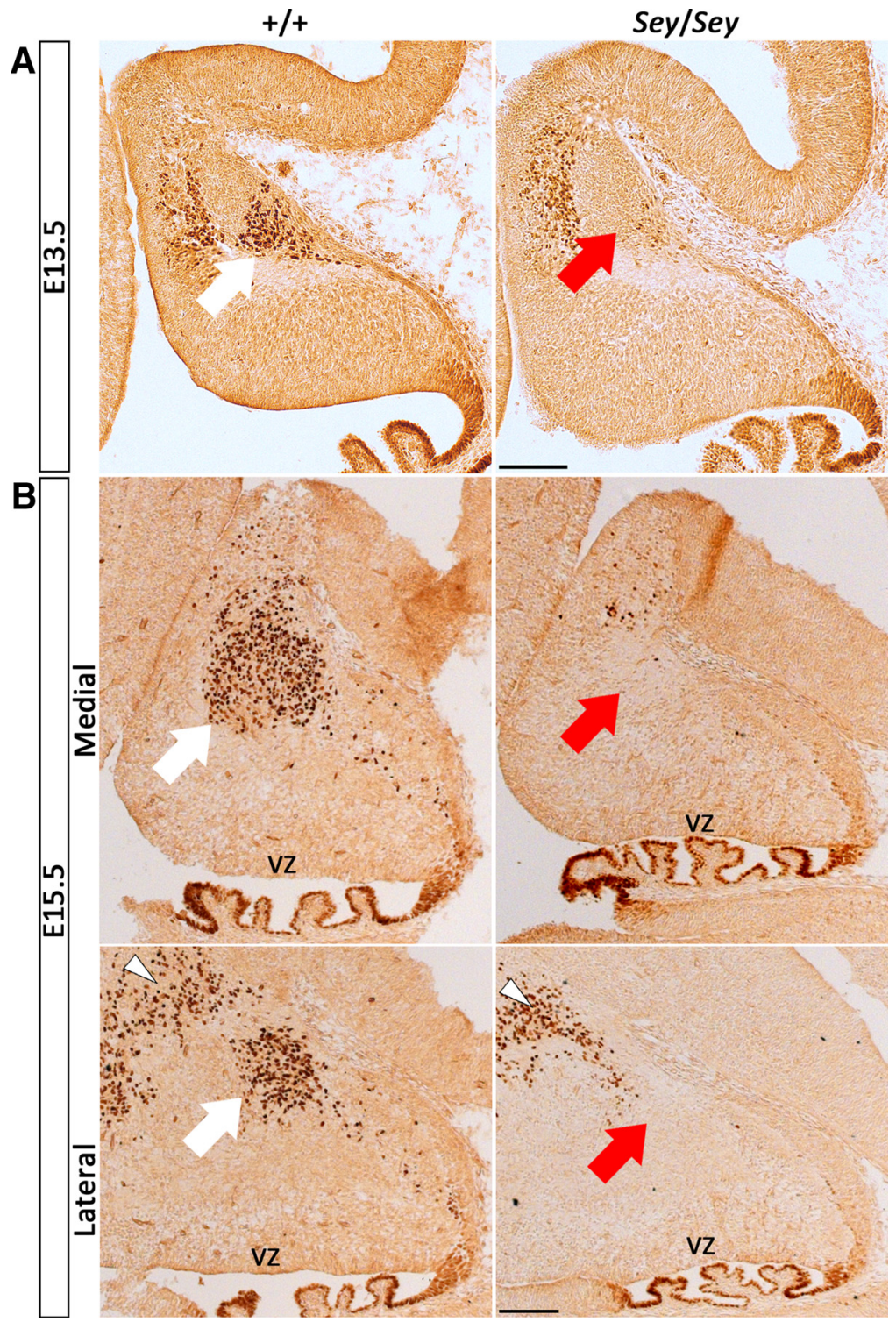

Figure 3. The lack of Pax6 in the Sey cerebellum results in the reduction of $\mathrm{Lmx}_{1 \mathrm{a}}{ }^{+}$cells in the cerebellar nuclei. $A, B, \operatorname{Lmx} 1 \mathrm{a}$ expression is observed in CN neuron progenitors that enter the NTZ of $(\boldsymbol{A})$ E13.5 and ( $\boldsymbol{B})$ E15.5 wild-type cerebellum (white arrows). In the E13.5 and E15.5 Sey cerebellum, $\mathrm{Lmx}^{+}{ }^{+}$cells are largely absent (red arrows). The lateral aspects of the cerebellum highlight the 3 cells ( $\boldsymbol{B}$, bottom, white arrowheads) which are generated from the VZ and give rise to extracerebellar neurons. These cells also express Lmx1a and are not altered in the Sey mutant. Scale bars, $100 \mu \mathrm{m}$.

Figure 2. The lack of Pax6 in the Sey-mutant cerebellum results in the absence of RL-derived $\mathrm{Tbr}^{+}{ }^{+} \mathrm{CN}$ neurons but no apparent loss of VZ-derived IIx $3^{+} \mathrm{CN}$ neurons. $A$, The transcription profile from CbGRiTS of Tbr 1 in the wild-type and Sey cerebellum atE13,E15, and E18. The Seycerebellum has a significant reduction in $T b r 1$ transcript at $\mathrm{E} 13$ and E15. $y$-axis $\log _{2}$ transformed and followed by a $2 Z+8 Z$-score stabilized intensity value for microarray dataset. $\boldsymbol{B}-\boldsymbol{D}$, Immunohistochemistry reveals that $\mathrm{Tbr} 1^{+}$cells are absent in the Sey cerebellum. Cells immunopositive for $\mathrm{Tbr} 1^{+}$are observed in the NTZ of the wild-type cerebellum (white arrows) at E13.5 (B), E15.5 (C), and E18.5 (D), but this Tbr ${ }^{+}$ cell population is absent in the Sey cerebellum (red arrows). A few Tbr1 ${ }^{+}$cells are observed in the lateral cerebellum of the E15.5 Sey mutant ( $\boldsymbol{C}$, blue arrowhead). These cells comprise only $2.7 \%$ $( \pm 0.4 \%)$ of the total number of Tbr $1^{+}$cells in the wild-type cerebellum. $E$, Immunohistochemistry of Tbr1 illustrates that the cerebellar expression of Tbr1 in heterozygous ( $\mathrm{Pax}^{\text {Sey/++}}$ ) atE13.5, E15.5, and E18.5 is not different from that of the wild-type littermates ( $\boldsymbol{B}-\boldsymbol{E}$, compare white arrows). $\boldsymbol{F}$, Immunohistochemistry of I Ix 3 over developmental time reveals that these $\mathrm{CN}$ neuron populations are similar in the cerebellum of the wild-type (top) and Sey (bottom) mouse at E11.5, E13.5, and E15.5. At $\mathrm{E} 11.5$, the IIx $3^{+} \mathrm{CN}$ neurons are largely seen outside of the VZ. By E13.5, Irx3 ${ }^{+} \mathrm{CN}$ neurons have entered the NTZ. By E15.5, the Irx $3^{+}$CN neurons have started to colonize the cerebellar core. Error bars represent SE. Scale bars, $100 \mu \mathrm{m}$.
In the E15.5 wild-type cerebellum, Lmxla is also expressed in a set of cells dorsal to the NTZ, termed the c3 cells (Chizhikov et al., 2006). These 33 cells give rise to extracerebellar neurons and do not originate from the cerebellar RL (Millen et al., 2014). Expression of Lmxla is unaffected in these cells in the Sey mutant (Fig. $3 B$, arrowheads), suggesting that Lmxla expression is independent of Pax6. Thus, the effect of the Pax6 null on Lmxla expression aligns with a specific loss of $\mathrm{CN}$ neurons.

\section{Cytoarchitecture of the Sey cerebellum indicates the loss of $\mathrm{CN}$ neurons}

The altered expression of Tbr 1 and Lmxla in the Sey cerebellum could suggest that either the glutamatergic $\mathrm{CN}$ neurons are present but fail to express the proper markers in the absence of Pax6 expression, or that $\mathrm{CN}$ neurons are deleted in the absence of Pax6 expression. To address this issue, we analyzed the cytoarchitecture of the wild-type and Sey cerebellum. In the wild-type cerebellum, nuclear neurons aggregate at the NTZ by E15.5 and can be readily visualized with cresyl violet staining (Fig. 4A, black arrow). In the Sey cerebellum, however, this nuclear mass is replaced by a fibrous and acellular matrix (Fig. $4 B$, red arrow). At E18.5, in the wildtype cerebellum, the $\mathrm{CN}$ cells from the NTZ occupy the deep portion of the cerebellum (Fig. 4C, black arrow). In the Sey cerebellum, however, there is no recognizable cellular aggregate in this region, suggesting the absence of $\mathrm{CN}$ neurons (Fig. 4D, red arrow).

\section{Increased cell death in the $\mathrm{CN}$ neuron progenitors of Sey cerebellum}

The absence of CN neurons in the Sey cerebellum could be due to the lack of generation of $\mathrm{CN}$ neuron progenitors from the RL. To address this possibility, we examined the earliest marker of $\mathrm{CN}$ neuron progenitors (i.e., Atoh1) in the Sey cerebellum to determine whether the $\mathrm{CN}$ neurons are initially generated in the mutant cerebellum. To do this, we crossed the Atoh1-reporter allele (Atoh $1^{\text {LacZ }}$ ) into the Sey mutant. In the E11.5 wild-type cerebellum, $\mathrm{CN}$ neuron progenitors that arise from the RL and migrate along the subpial stream express Atoh 1 as indicated by $\beta$-gal-immunopositivity (Fig. $5 A$, arrows). Surprisingly, Atoh $1^{+}$cells are observed at the RL and subpial stream of the E11.5 Sey cerebellum (Fig. 5B, arrows). Quantitatively, the number of Atoh $1^{+}$cells in the Sey cerebellum is not significantly different from the wild type $(p=0.31)$. This finding indicates that $\mathrm{CN}$ neuron progenitors are produced from the RL even in the absence of Pax6.

As the production of $\mathrm{CN}$ neuron progenitors is unaffected in the Sey cerebellum, the loss of $\mathrm{CN}$ neurons found later in development could be a result of a change in cell fate or of enhanced cell death in the $\mathrm{CN}$ neuron progenitors. To determine whether 
$\mathrm{CN}$ neuron progenitors have changed cell fate, we performed BrdU incorporation to mark the cells generated between E10.5 and E11.5, and analyzed the fate of these cells at E15.5. In the E15.5 wild-type cerebellum, the majority of the $\mathrm{BrdU}^{+}$cells are found in the NTZ, with a few $\mathrm{BrdU}^{+}$ cells scattered above the VZ, and the EGL is devoid of $\mathrm{BrdU}^{+}$cells. In contrast, the Sey cerebellum lacks $\mathrm{BrdU}^{+}$cells in the NTZ and no ectopic BrdU ${ }^{+}$cells are detected. BrdU-labeled cells are observed in the rest of the mutant cerebellum as in the wild-type cerebellum. These findings suggest that $\mathrm{CN}$ neuron progenitors have not undergone cell-fate change, but have disappeared from the Sey cerebellum.

The alternative explanation of cell death in the $\mathrm{CN}$ neuron progenitors can be explored using activated caspase- 3 immunopositivity as a marker for apoptosis in the developing cerebellum. In the E12.5 cerebellum of normal and mutant embryos, the numbers of cells that are caspase $-3^{+}$are not significantly different. However, starting from E13.5, and more obvious by E15.5, the Sey cerebellum exhibits significantly increased numbers of caspase- $3^{+}$cells. The majority of caspase $-3^{+}$cells in the E13.5 Sey cerebellum is localized to the anterior EGL, and few cells are found near the presumptive NTZ. At E15.5, the caspase- $3^{+}$cells are restricted to the anterior EGL (Fig. 5D, arrowheads). Caspase $-3^{+}$cells are rarely observed in the wild-type cerebellum at any of the examined ages (Fig. 5C; data not shown). Quantitatively, the number of caspase$3^{+}$cells in the E13.5-E18.5 Sey cerebellum is 4-28-fold higher than in the wild-type cerebellum, and the differences between the Sey mutant and the wild type are significant (Fig. 5E). As caspase$3^{+}$cells are found in the EGL, we sought to determine whether these dying cells are GCs or non-GCs (i.e., likely $\mathrm{CN}$ neuron progenitors) using a GC marker, Insm1 (Duggan et al., 2008). At E13.5 and E15.5 in both wild-type and Sey cerebella, Insm1 is robustly expressed in the cells of the EGL, while $\mathrm{CN}$ neurons in the NTZ are immunonegative for Insm1 (Fig. $5 F, G$; data not shown). Double-labeling of Insm1 and caspase-3 reveals that caspase-3 immunopositivity is present in both Insm $^{+}$and Insm $1^{-}$cells (Fig. 5H). However, in the E13.5 and E15.5 Sey cerebellum, 75.9 and $76.3 \%$, respectively, of all caspase- $3^{+}$cells are negative for Insm 1 expression, indicating that the majority of the dying cells are likely not GCs (Fig. 5I).

\section{Chimera analysis revealed that Pax6 is an extrinsic factor that controls the survival of $\mathrm{CN}$ neurons}

Our data indicate a requirement of Pax6 in the survival of $\mathrm{CN}$ neuron progenitors. Pax6 may act as a cell-intrinsic or a cellextrinsic factor for the survival of $\mathrm{CN}$ neurons. To address this issue, we examined experimental chimeras from wild-type and Pax6-null embryos (i.e., Sey/Sey $<->+/+$ ). The chimeric experiment affords the opportunity to determine how a wildtype environment impacts the survival of mutant cells and vice versa. If Pax6 acts as a cell-intrinsic factor for cell survival, we hypothesize that Pax6-null mutant cells do not give rise to $\mathrm{CN}$ neurons, and all $\mathrm{CN}$ neurons are wild type in the chimeric cerebellum. On the other hand, if Pax6 is an extrinsic factor for cell survival, Pax6-null cells can give rise to CN neurons.

The 25 experimental chimeras used in this analysis were generated from one embryo that came from a mating of heterozygous Pax6-null $($ Sey/t) mice and another embryo from a mating of wild-type mice $\left(+\mathrm{GFP} /+{ }^{\mathrm{GFP}}\right)$. This combination should lead to approximately one-fourth of the chimeras being of Sey/Sey genotype. We examined the chimeric embryos at E18.5, and three embryos had a cellular contribution from Pax6-null mutant embryos, and each of these embryos exhibited craniofacial defects characteristic of the Sey mutant. The quantitative analysis of percentage chimerism (see Materials and Methods) estimated that these embryos comprised $0.6,9.9$, and $23 \%$ wild-type cells. To determine the phenotype of $\mathrm{CN} / \mathrm{Tbr}^{+}$cell loss in these chimeras, we examined the wild-type, Sey, and chimeric cerebellum. In the wildtype cerebellum, counts of $\mathrm{Tbr}^{+}$cells in the $\mathrm{CN}$ region averaged 817 per whole cerebellum. This was compared with only $43 \mathrm{Tbr}^{+}$cells in the $\mathrm{CN}$ region of the Pax6-null cerebellum. However, in the three chimeras, we counted 89,167 , and $178 \mathrm{Tbr}^{+}$cells in the CN (Fig. 6A). These numbers of Tbr $1^{+}$ cells in the $\mathrm{CN}$ trended with the percentage of chimerism.

In the cerebellar nuclear region of all three mutant chimeras, we found that $\mathrm{Tbrl}^{+}$cells were both GFP-positive and GFPnegative (Fig. $6 B-D$ ). These data indicate that the $\mathrm{Tbr}^{+}$cells of the $\mathrm{CN}$ are of both wild-type and Pax6-null lineage. The cell- 

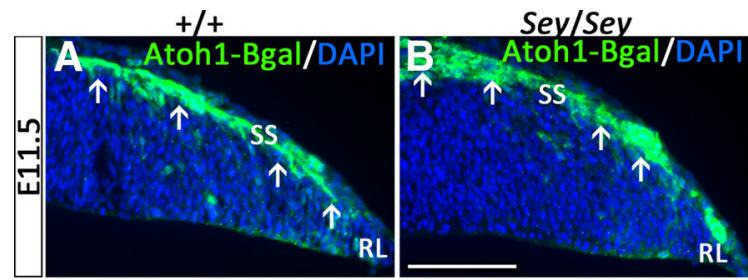

E

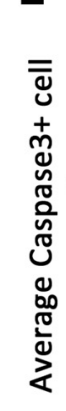
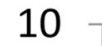

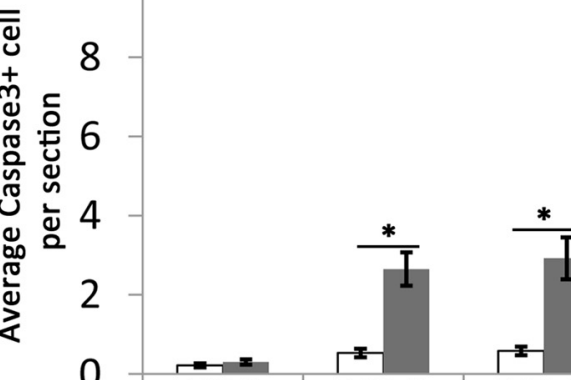

Cell Death

\begin{tabular}{cc} 
& $\mathrm{E} 12.5$ \\
Fold change & $\mathbf{0 . 4}$ \\
\hline$P$-Value & 0.37
\end{tabular}

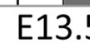

E13.5
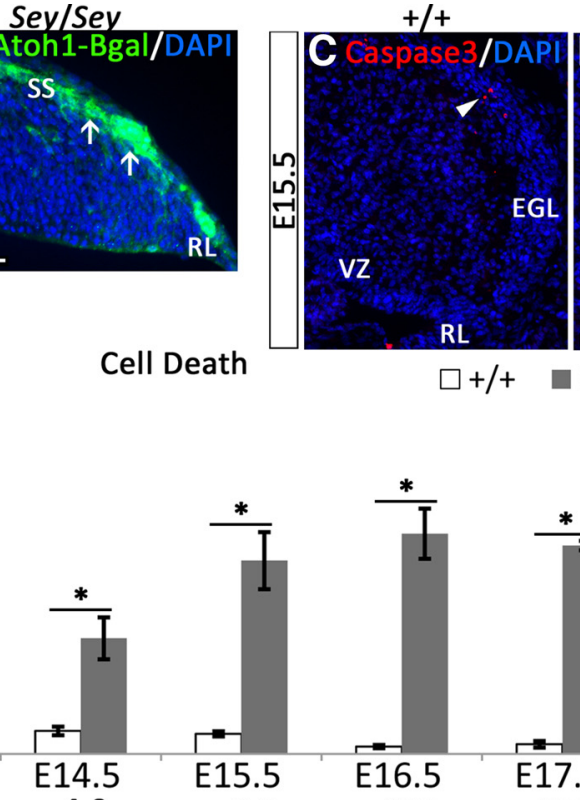

Sey/Sey

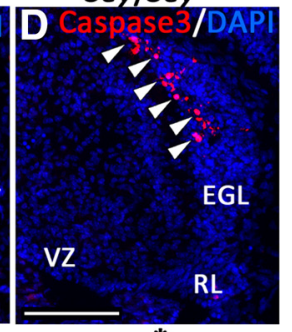

$\square+/+\quad \square$ Sey
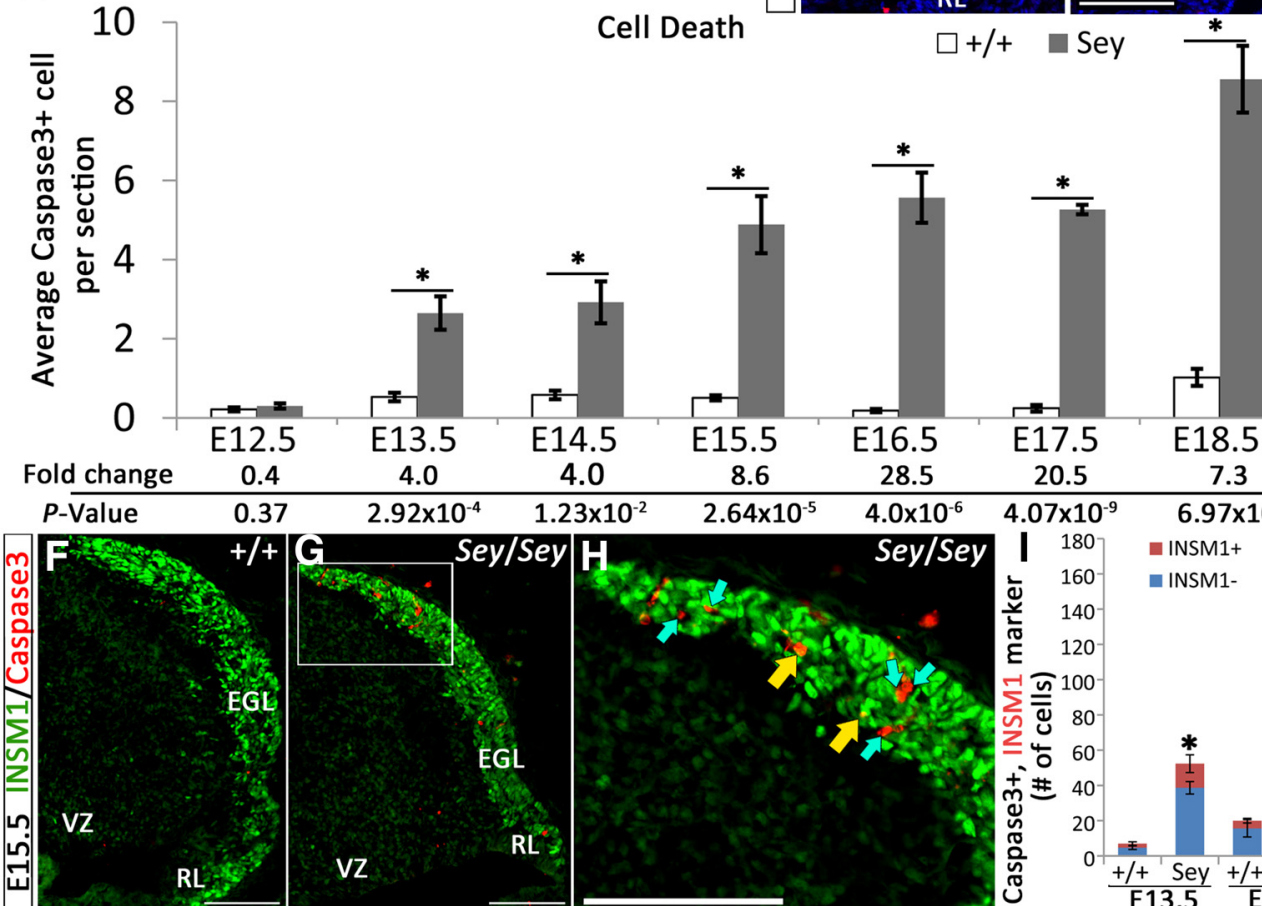

\section{0}

E15.5

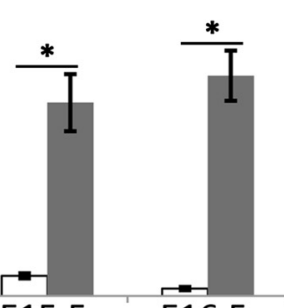

E16.5

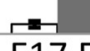

E17.5

20.5

$4.07 \times 10^{-9} \quad 6.97 \times 10^{-6}$
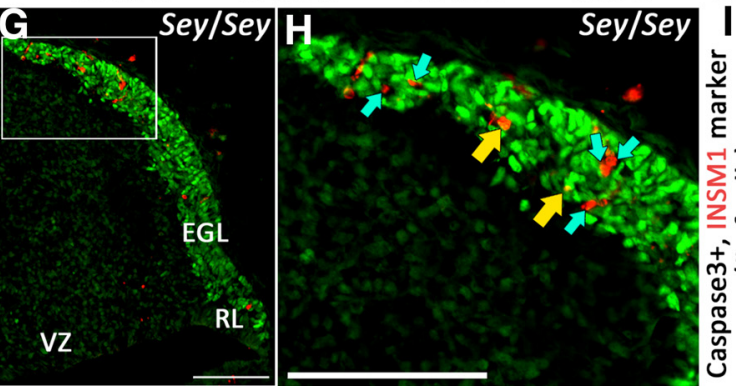

$2.64 \times 10^{-5}$

$4.0 \times 10^{-6}$

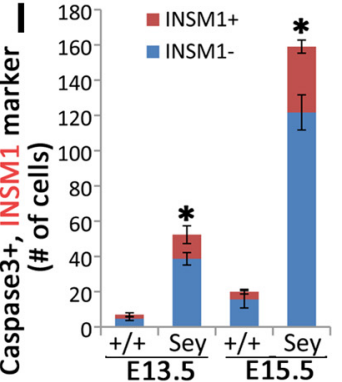

Figure 5. CN neuron progenitors are generated in the Sey-mutant cerebellum but exhibit enhanced cell death. $A$, In the E11.5 wild-type $\left(\right.$ Pax $6^{+/+} ; A$ toh $\left.1^{+/ L a c z}\right)$ cerebellum, $C \mathrm{CN}$ neuron progenitors express Atoh1 when the cells emerge from the RL and during migration along the subpial stream (arrows). $\boldsymbol{B}$, A similar pattern of Atoh1-expressing cells is observed in the Sey-mutant (Pax6 $6^{\text {sey/sey }}$; Atoh1 ${ }^{+/ \text {LacZ }}$ ) cerebellum (arrows). C $-E$, Cell death is assessed by immunolabeling for activated caspase-3 and quantified at E12.5-E18.5 in wild-type and Sey cerebella. $\boldsymbol{C}, \boldsymbol{D}$, The majority of cells undergoing cell death in the wild-type and Sey cerebellum are observed at the anterior of the EGL (arrowheads). $\boldsymbol{D}$, There is a dramatic increase in caspase $3^{+}$cells in the mutant EGL. $\boldsymbol{E}$, The Sey cerebellum shows significantly higher numbers of anti-caspase- $3^{+}$cells than that in the wild-type at E13.5 and later $\left({ }^{*} p<0.005\right) . \boldsymbol{F}-\boldsymbol{H}$, Double-labeling with Insm1, a GC-specific marker, and caspase-3 reveals that most of the dying cells in the Sey cerebellum are non-GCs. GCs robustly expressed Insm 1 in the wild-type $(\boldsymbol{F})$ and $\operatorname{Sey}(\boldsymbol{G})$ EGL. Highlighted area in $\boldsymbol{G}$ is shown in $\boldsymbol{H}$ at higher magnification. $\boldsymbol{H}$, In the Sey EGL, most caspase-3 ${ }^{+}$cells are Insm 1-negative (blue arrows) and few cells coexpress Insm1 and caspase-3 (yellow arrows). I, Proportion of caspase- $3^{+}$cells that are Insm1-positive (pink) or Insm1-negative (blue) in the E13.5 and E15.5 wild-type and Sey EGL. The Sey cerebellum exhibits a significantly increased number of total anti-caspase- $3^{+}$cells than the wild type at both E13.5 and E15.5 $\left({ }^{*} p<0.005\right)$. SS, Subpial stream. Error bars represent SE. Scale bars, $100 \mu \mathrm{m}$.

intrinsic hypothesis predicts that cell genotype linearly correlates with cell phenotype. This is testable by calculating the expected number of Tbr $1^{+}$cells based on the percentage chimerism, and comparing this to the observed number of Tbr $1^{+} \mathrm{CN}$ cells (e.g., in a $50 / 50$ chimera we would expect $(0.5 \times 817)+(0.5 \times 43)=430$ $\mathrm{Tbr}^{+}$cells]. A $\chi^{2}$ test reveals that the actual numbers of $\mathrm{Tbr} 1^{+}$ cell observed in these chimeric cerebella are significantly different from the expected numbers of Tbr $1^{+}$cells estimated $(P$ value $=$ $1.18 \times 10^{-14}$; Fig. $6 A$ ). Thus, we rejected the null hypothesis and accept the alternative hypothesis that Pax6 acts as an extrinsic factor on the survival of $\mathrm{CN}$ neurons.

\section{Characterization of the reduction of $\mathrm{Tbr}^{+} \mathrm{UBCs}^{+}$in the Pax6-null cerebellum}

The UBCs are RL derivatives generated at late embryonic times starting from E15, and the progenitors can be identified by Tbr2 expression (Fink et al., 2006). In the E15.5 wild-type cerebellum, the newly generated UBC precursors appear as a stream of $\mathrm{Pax}^{+} / \mathrm{Lmx} \mathrm{a}^{+} / \mathrm{Tbr}^{+}$cells in the RL (Fig. $7 A-C$ ), and continue to express these molecules as the UBCs migrate into the cerebellar core at E18.5 (Figs. $7 E, F, 8 B$, white arrows).

Our Pax6 transcriptome data reveals a downregulation of Tbr2 expression in the Sey cerebellum throughout embryonic development, with a threefold reduction at E18.5 (Fig. 7D; Ha et al., 2012). Immunolabeling for Tbr2 in the E18.5 Sey cerebellum reveals that $\mathrm{Tbr} 2^{+}$cells are absent from the medial cerebellar core (Fig. 7G), but some weak Tbr2-immunopositive cells are observed in the region of the RL at more lateral levels (Fig. $7 \mathrm{H}$, white arrows). Quantitative analysis indicated an $86.9 \%$ loss of Tbr $2^{+}$ cells from the E18.5 Sey cerebellum compared with the wild-type cerebellum $\left(p=7.71 \times 10^{-5}\right)$.

\section{Reduction of $\mathrm{Lmxla}^{+}$cells in the Sey cerebellum}

We determined the expression of Lmxla in the wild-type and Pax6-null cerebellum at E15.5-E18.5. In the E15.5 wild-type cerebellum, there are cells with strong Lmxla staining in the area between the EGL and the cerebellar core (Fig. 8A, left, arrowheads). Such staining is absent in the Sey cerebellum (Fig. $8 A$, 
right). However, there are Lmxla-positive cells, such as the late-born GC progenitors, that have similar staining profiles in the wild-type and Sey RL. Likewise, the denser Lmxla staining of cells in the choroid plexus is similar between the wildtype and Sey brain (Fig. 8A). The Lmxla positivity in the Sey-mutant cerebellum supports the notion that Lmxla expression is independent of Pax6.

At E18.5, Lmxla in the wild-type cerebellum is expressed by the UBCs in the RL and those migrating into the cerebellar core (Fig. $8 B$, arrowheads). In the Sey cerebellum, similar to the effect on the aforementioned $\mathrm{Tbr}^{+}$expression, $\mathrm{Lmxla}^{+}$ cells are absent at the medial level, but can be observed at more lateral levels (Fig. $8 B$, bottom right, arrowheads). For the whole cerebellum at E18.5, there is a $63.7 \%$ diminution of Lmxla ${ }^{+}$cells in the Sey cerebellum compared with the wild type ( $p=$ $\left.4.56 \times 10^{-3}\right)$. These observations indicate a specific loss of Lmxla in the UBC population of the Sey cerebellum.

Cytoarchitecture of the Sey cerebellum indicates the loss of UBCs

To determine whether the loss of Tbr2 and Lmxl expression is a deficiency in gene expression or the loss of UBCs in the Sey, we examined the cytoarchitecture of the RL region with cresyl violet staining. Medially, there is a dense population of cells in the wild-type RL region where UBCs are normally found, and this same region is devoid of cells in the Sey cerebellum (Fig. 4C,D, regions bounded by red dotted lines). As found with anti-Tbr2 and anti-Lmxla immunostaining, cresyl violet staining revealed the presence of cells in the lateral RL regions of the Sey cerebellum (Fig. 4E,F, regions bounded by red dotted lines). These results confirm the loss of UBCs in the medial Sey RL.

Increased cell death and decreased cell production in the UBC germinal zone of the Sey cerebellum

The reduction of UBCs seen in the Sey cerebellum could be the result of an enhanced cell death and/or a reduced generation of UBCs. We compared the number of caspase- $3^{+}$cells between wild-type and Sey cerebella during the genesis of UBCs at E15.5-E18.5 (Fig. 9A). A moderate, and significant, increase in the number of caspase $-3^{+}$cells was found in the mutant RL at E16.5 (Fig. 9B).

To address whether a decrease in UBC production is contributing to the Sey-mutant UBC phenotype, we analyzed cell production at the RL during the period of UBC neurogenesis by acute BrdU labeling. Interestingly, we find that the area of the Sey $\mathrm{RL}$ is $56 \%$ smaller than the wild-type $\mathrm{RL}$ at E16.5 $(p=1.44 \times$ $10^{-5}$; Fig. 9C,D). Furthermore, the total number of $\mathrm{BrdU}^{+}$cells in the RL is reduced by $51 \%$ in the Sey mutant $\left(p=1.39 \times 10^{-4}\right.$; Fig. $9 C, E)$. The reduction of $\mathrm{BrdU}^{+}$cells in the mutant $\mathrm{RL}$ is not a result of changes in cell proliferation as the labeling indices are

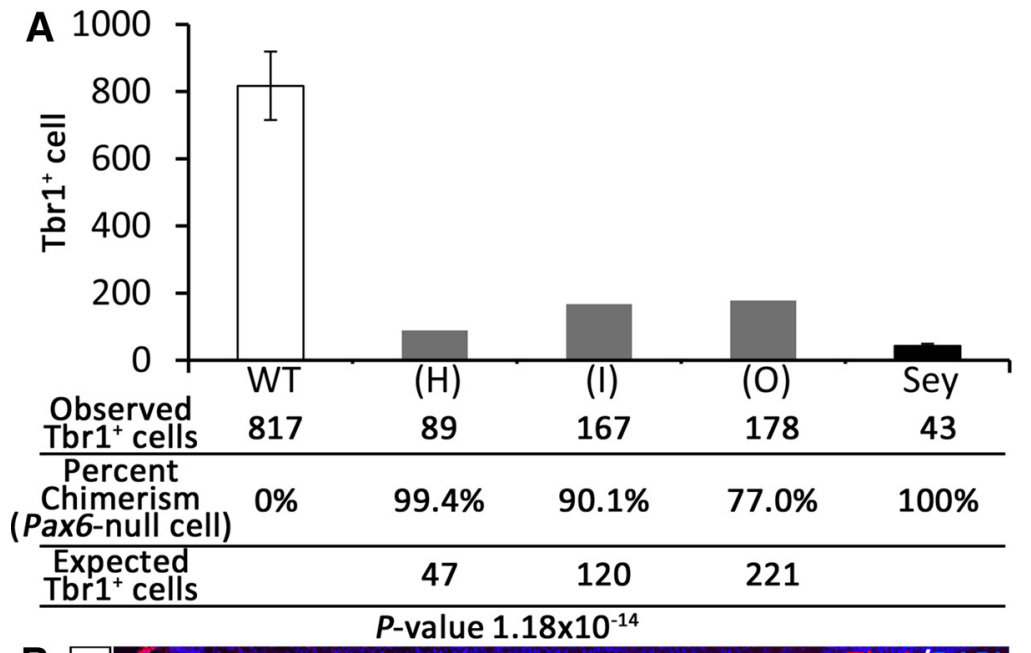

Figure 6. Experimental chimera analysis demonstrates that Pax6 can be cell-extrinsic for CN neuron survival. Experigenotype are examined for the phenotype of $\mathrm{CN}$ neuron survival. $\boldsymbol{A}$, Quantitative analysis of the number of $\mathrm{Tbr}^{+}{ }^{+}$cells in wild-type, Sey-mutant, and Sey-chimeric cerebella. Expected numbers of $\mathrm{Tbr}^{+}{ }^{+}$cells for each chimera are calculated from bers of $\mathrm{Tbr}^{+}$cells in the chimeric cerebella are significantly different from the expected numbers. $\boldsymbol{B}$, Cells positive for (

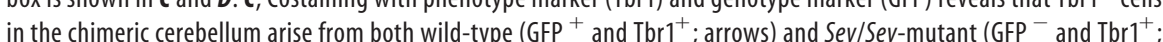
arrowheads) genotypes. D, This image more clearly shows the mutant $\mathrm{Tbr}^{+}$cells (arrowheads) and wild-type Tbr ${ }^{+}$cells (arrows). CP, Choroid plexus. Error bars represent SE. Scale bars, $100 \mu \mathrm{m}$.

similar between wild-type and Sey RL (Fig. 9F; in fact the Sey RL has a marginally higher labeling index than the wild-type RL). These data indicate that both enhanced cell death of UBCs and a markedly decreased pool of RL progenitors lead to the Seymutant UBC phenotype.

\section{Discussion}

Pax6 is a prominent gene involved in the development of multiple CNS regions and sensory organs (Walther and Gruss, 1991). The Sey cortex, which lacks the Pax6 gene, exhibits a dramatic reduction in cortical neurogenesis and disruption of cortical lamination (Schmahl et al., 1993; Quinn et al., 2007). However, in the Sey cerebellum, there is only minor disorganization of the EGL with foliation defects and no apparent GC loss (Engelkamp et al., 1999; Swanson et al., 2005). This is surprising because Pax6 is richly expressed in the cells of the RL, which produces GCs, the most numerous neurons in the brain, as well as other neurons of the glutamatergic lineage. Pax6 is expressed sequentially by all RL 


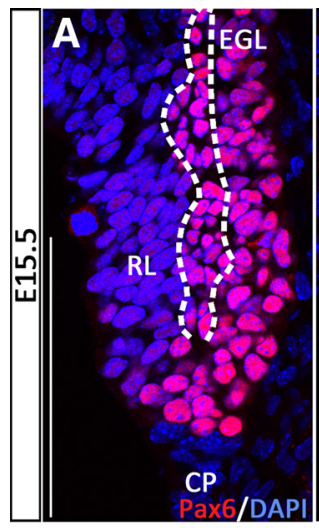

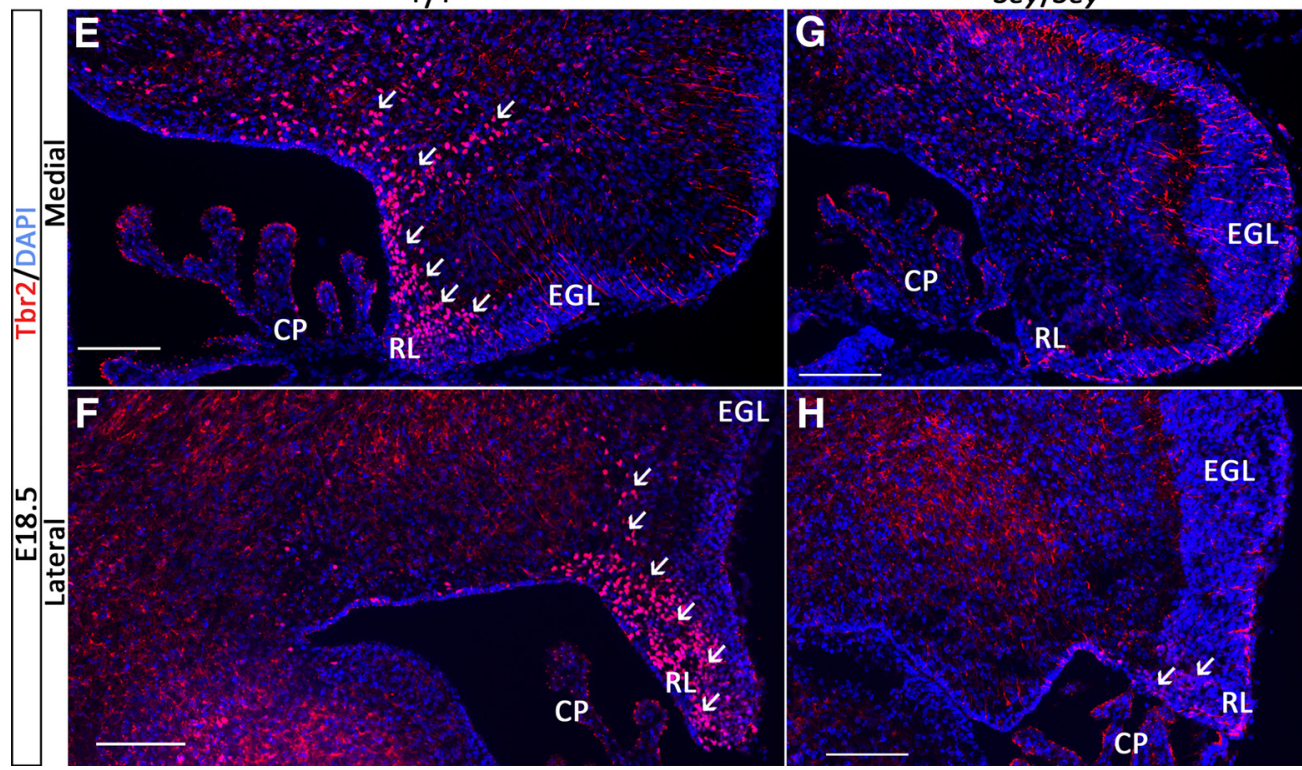

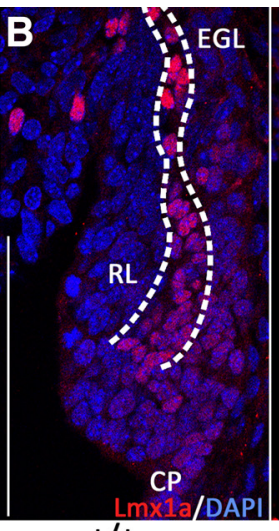

$+/+$

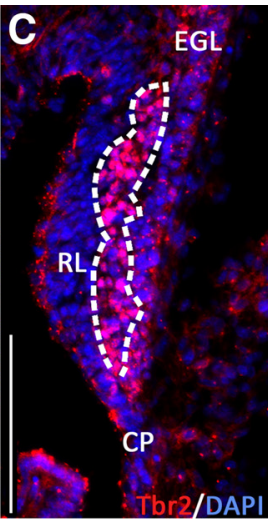

DAP

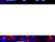

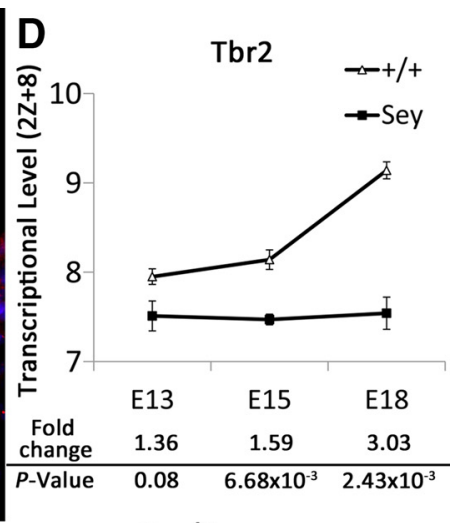

Sey/Sey

Figure 7. The loss of Pax6 results in the absence of Tbr2 ${ }^{+}$cells from the medial Sey cerebellum. $\boldsymbol{A}-\boldsymbol{C}$, In the normal $\mathrm{E} 15.5$ cerebellum, immunohistochemistry reveals that Pax6 $(\boldsymbol{A})$, Lmx1a $(\boldsymbol{B})$, and Tbr2 (C) label a stream of cells (within the dashed lines) found between the EGL and the interior face of the RL. $\boldsymbol{D}$, The transcription level of Tbr2 in the Sey cerebellum is significantly reduced at E15.5 and E18.5 as revealed by Pax6 transcriptome analysis from CbGRiTS. $y$-axis $\log _{2}$ transformed and followed by a $2 Z+8 Z$-score stabilized intensity value for microarray dataset. $\boldsymbol{E}, \boldsymbol{F}$, In the E18.5 wild-type cerebellum, expression of Tbr2 is observed in the UBCs moving out of the RL into the developing cerebellar core (arrows). $\boldsymbol{G}$, In contrast, $\mathrm{Tbr2}^{+}$cells are absent from the RL and cerebellar core of the Sey cerebellum at medial levels. $\boldsymbol{H}$, Some Tbr2-positive cells are observed more laterally in the Sey cerebellum (arrows). CP, Choroid plexus. Error bars represent SE. Scale bars, $100 \mu \mathrm{m}$.

derivatives: the glutamatergic $\mathrm{CN}$ neurons, GCs, and UBCs. The Sey phenotypes of CN neurons and UBCs have not been previously reported. Our findings identify major, and heretofore unreported, functions for Pax6 in the development of glutamatergic $\mathrm{CN}$ neurons and UBCs. This supports a more critical role for Pax6 in the molecular architecture of the developing cerebellum.

\section{The role of Pax6 in glutamatergic CN neuron development}

Expression of Pax6 marks the progenitors of glutamatergic $\mathrm{CN}$ neurons before the expression of cell-specific markers (e.g., Tbr1, Tbr2, and Lmx1a), which are expressed when the cells enter the NTZ (Fink et al., 2006; current study). In the Sey cerebellum, these downstream cell markers are absent and the NTZ is acellular, indicative of the loss of the CN neuron population. The finding of Atoh $1^{+} \mathrm{CN}$ neuron progenitors in the E11.5 Sey subpial stream indicates there is normal cell production. However, these Atoh $1^{+}$cells do not colonize the NTZ and we observed an increased number of caspase $-3^{+}$cells in the Insm1-negative, likely $\mathrm{CN}$ neuron, population of the Sey subpial stream/EGL. This finding indicates that the migration of CN neurons to the NTZ is disrupted in the Sey mutant and cell death seems to be a critical factor for the loss of CN neurons. Interestingly, our study of Sey chimeras demonstrates a cell-extrinsic role in $\mathrm{CN}$ neuron survival in the mutant condition; that is, the presence of Pax6 wildtype cells rescues Pax6-null CN neurons.

Our observation that glutamatergic $\mathrm{CN}$ neurons exhibit cell death when Pax6 is removed points to a novel pathway mediated by Pax6 that promotes cell survival in the cerebellum. In other brain regions, Pax6 has been shown to regulate cell survival by controlling the expression of proapoptotic or antiapoptotic factors. For example, Pax6 is required for the survival of cortical radial glial cells by downregulating the expression of neurotrophin receptor $\mathrm{p} 75^{\mathrm{NTR}}$, which is known for its proapoptotic activity (Nikoletopoulou et al., 2007). On the other hand, Pax6 promotes the survival of dopaminergic olfactory bulb neurons by upregulating the expression of crystalline $\alpha \mathrm{A}$, an antiapoptotic molecule that inhibits the activation of caspase-3 (Ninkovic et al., 2010). In the cerebellum, our Pax6 transcriptome analysis identified a downregulation of Bcl2l13 and neurotrophin-3 (Ntf3) in the Sey mutant (Ha et al., 2012). Bcl2113 is an antiapoptotic molecule that protects mitochondrial membrane integrity, which in 

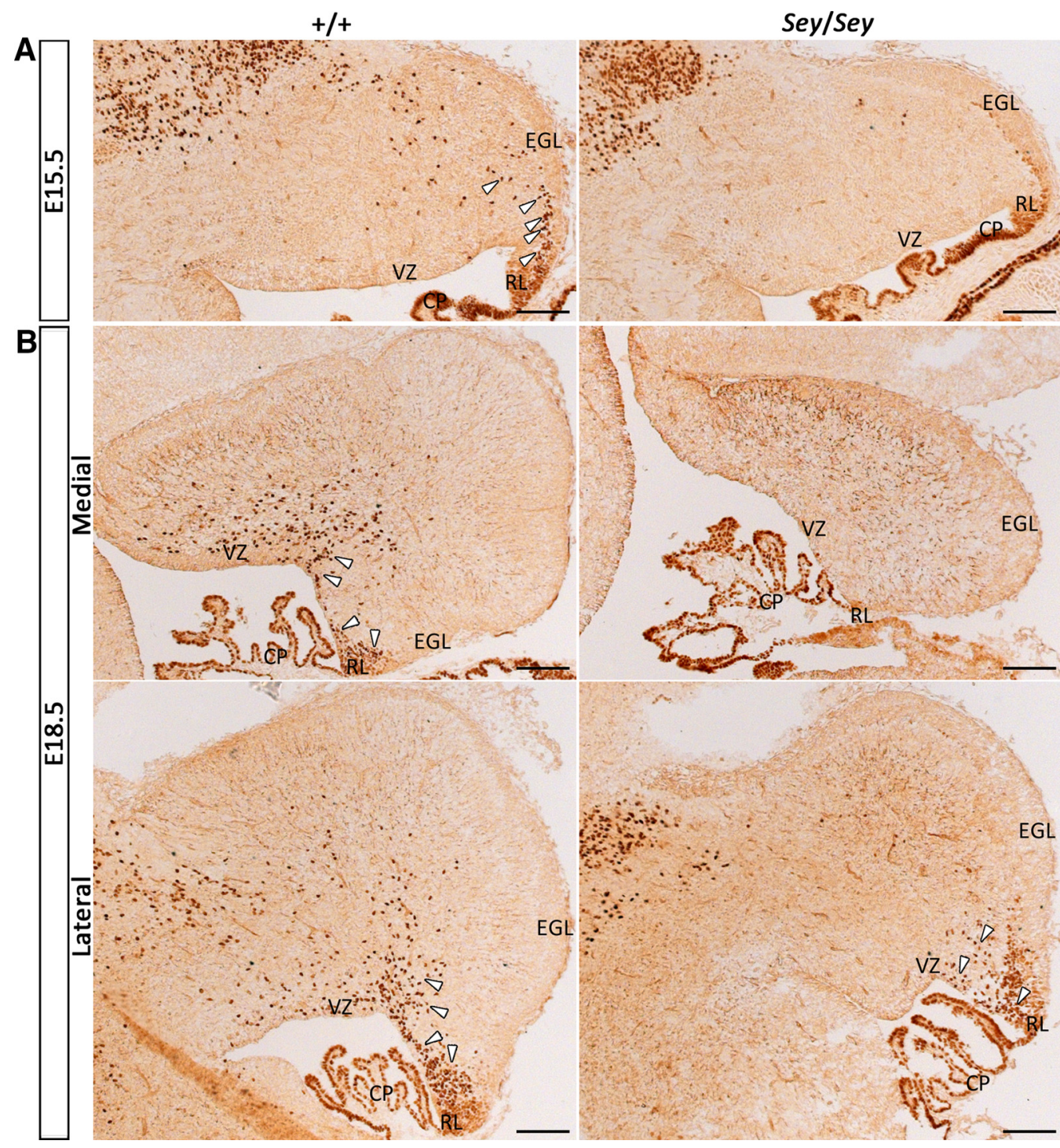

Figure 8. The loss of Pax6 results in a reduction of $L m x 1 a^{+}$cells in the Sey cerebellum. A, At E15.5, UBC progenitors with strong Lmx1a expression (left, white arrowheads) are missing in the Sey cerebellum (right). By contrast, cells with light Lmx1a expression, which are GC progenitors born about the same time as UBCs, have similar staining in cells of the wild-type and Sey RL. B, At E18.5, cells with Lmx1a expression in the wild-type cerebellum (left, white arrowheads) are absent from the Sey medial cerebellar core (right). Lmx1a ${ }^{+}$cells are seen in the wild-type, lateral cerebellum (bottom left, white arrowheads), which are also observed in lateral portions of the E18.5 Sey cerebellum (bottom right, white arrowheads). CP, Choroid plexus. Scale bars, $100 \mu \mathrm{m}$.

turn inhibits mitochondria-driven apoptosis (Jensen et al., 2014). $\mathrm{Ntf3}$ is classically considered a prosurvival factor by binding the tyrosine kinase receptors (Maisonpierre et al., 1990; DiCiccoBloom et al., 1993). Recently, the precursor form of Ntf3 has also been identified for its proapoptotic activity when binding to p75 ${ }^{\text {NTR }}$ (Shen et al., 2013).

The role of Pax6 in UBC development

The absence of Pax6 also impacts the late-born UBCs. We found that during normal development, UBCs residing in the region between the RL and EGL express Pax6, Tbr2, and Lmxla. In the Pax6-null cerebellum, Tbr2-expressing and Lmxla-expressing UBCs are completely absent from the medial Sey cerebellum, although a few $\mathrm{Tbr}^{+} / \mathrm{Lmxla}^{+}$cells are observed in the lateral RL. During the time of UBC genesis, we detected a significant increase in the number of caspase $-3^{+}$cells in the Sey RL region, where UBCs are generated and reside before their dispersion into the cerebellar core; indicating that some UBC progenitors undergo cell death in the Pax6-null cerebellum. However, the number of apoptotic cells in the Sey RL is insuf- ficient to account for the missing Tbr2 ${ }^{+} \mathrm{UBCs}$ as cell death is only marginally increased at E16, and not different at E15, E17, and E18. In addition to cell death, we detected a deficit in cell production at the RL, the progenitor pool of RL lineages, in the Sey cerebellum. The E16 Sey RL is half the size of the wild-type RL and consists of 50\% fewer proliferating cells, as demonstrated by BrdU analysis. Our data indicate that the major role for Pax6 in UBC development is the regulation of production with a minor role being in regulating cell death.

\section{Revising the role of Pax6 in GC development}

Previous studies have shown that Pax6 regulates the migration and differentiation, and not the survival or production, of GCs (Engelkamp et al., 1999; Swanson et al., 2005; Swanson and Goldowitz, 2011). Our caspase-3 immunolabeling, however, revealed that some Insm $1^{+}$GCs in the Sey EGL underwent cell death during development. The discrepancy may lie in the different tissue processing and staining that we used compared to processing and staining used by Engelkamp et al. 

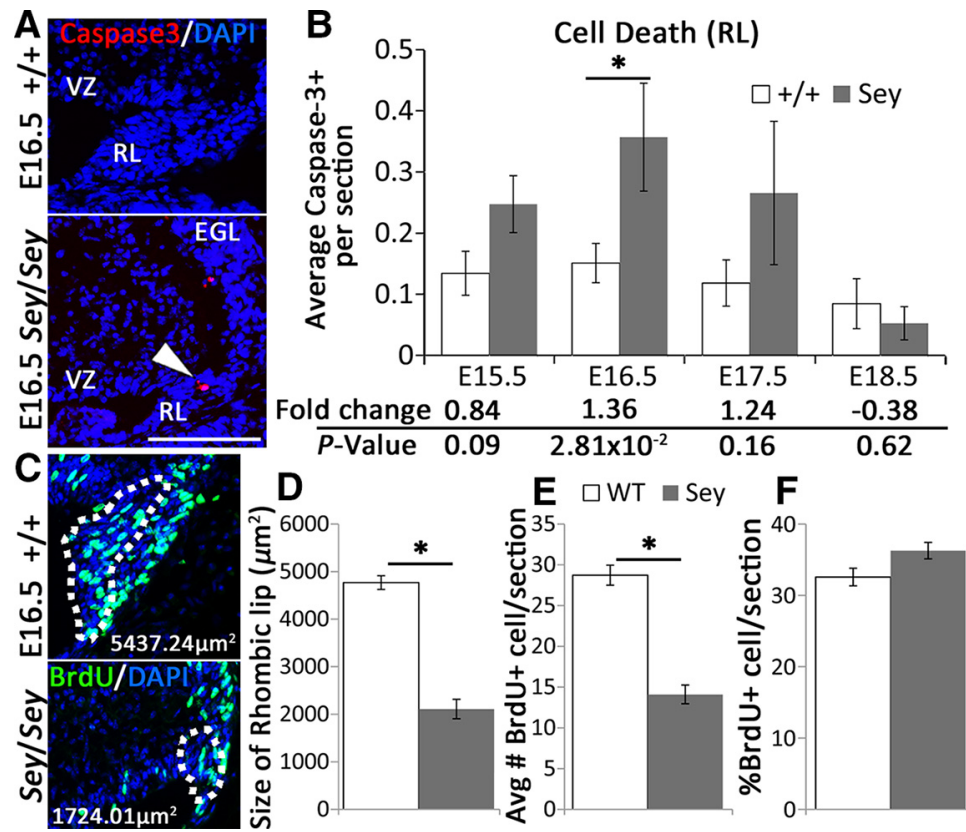

Figure 9. Enhanced cell death and decreased neurogenesis leads to the reduction of UBCs in the Sey cerebellum. $\boldsymbol{A}$, Activated caspase-3 immunopositivity indicates the absence of apoptotic cells in the E16.5 wild-type cerebellum while caspase- ${ }^{+}$cells are found in the RL of E16.5 Sey cerebellum (arrowhead). B, Quantitative analysis of caspase-3 immunopositivity revealed a significant increase in cell death in the Sey cerebellar RL at E16.5 compared to the wild type $\left.{ }^{*} p<0.005\right)$. $(-\boldsymbol{E}$, The RL (C, area bounded by dotted lines) of E16.5 wild-type and Sey cerebella demonstrates the mutant RL is significantly smaller (D) and has significantly fewer BrdU ${ }^{+}$cells $(\boldsymbol{E})$ compared with the wild type $\left(^{*} p<0.005\right)$. $\boldsymbol{F}$, Interestingly, the percentage of BrdU ${ }^{+}$cells in the Sey RL is slightly higher than that in the wild type. Error bars represent SE. Scale bars, $100 \mu \mathrm{m}$.

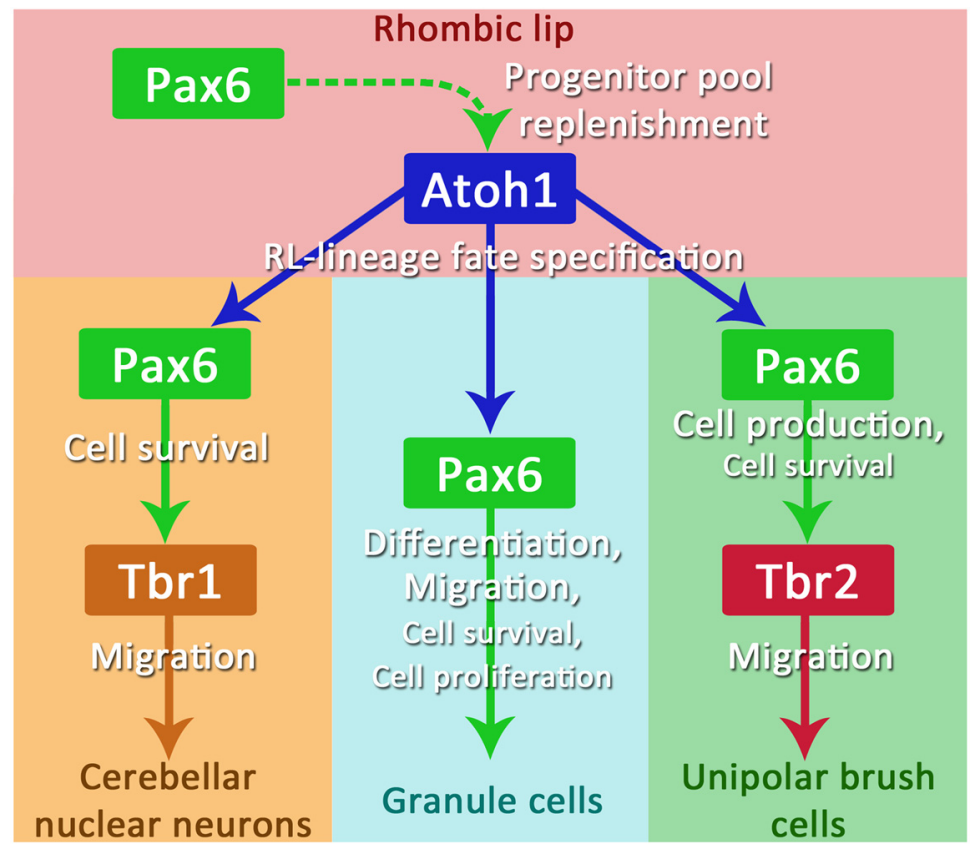

Figure 10. A model molecular program underpinning the development of cerebellar glutamatergic neurons. Expression of Atoh1 in the RL is required to specify progenitor cells to RL lineages. Pax6 is subsequently expressed in all RL-derived glutamatergic neurons and regulates multiple developmental processes in these cell types. In the development of CN neurons, Pax 6 regulates cell survival of progenitors. The present study identifies an enhanced cell death in the Pax6-null cerebellum that contributes to the loss of $\mathrm{CN}$ neurons. It is known that expression of Tbr1 regulates the migration of CN neurons and we find this is downstream of Pax6 function. In the development of UBCs, the survival and production of UBC progenitors require Pax6 function. Thus, in the Pax6-null mutant there is an enhanced cell death and reduction in UBC progenitor cells, which results in a reduction of UBCs. Tbr2 functions downstream of $\mathrm{Pax} 6$, and plays a role in UBCs migration. In the development of granule cells, the current findings suggest that Pax6 plays a role in cell survival and cell proliferation, in addition to cell differentiation and migration. Our current work also suggests an earlier function of Pax6 in regulating the replenishment of the RL progenitor pool.
The previous work found no effect of the Pax6-null mutation on GC proliferation in the EGL (Engelkamp et al., 1999). However, we do see a reduction in cell proliferation in the Sey RL at late embryogenesis. We have interpreted this as an effect on UBC genesis. However, we cannot exclude the possibility that it also impacts the generation of lateborn GCs. In this manner, the Sey mutation may have an upstream impact on GC production.

A spatial role of Pax6 in the development of $R L$ derivatives

We find that Pax6 has a global effect on the spatial organization of RL-derived cerebellar neurons in a lateral-medial fashion. We had an inkling of the spatial effect of the Sey from our analysis of Pax6 experimental chimeras, where we found that Pax6-null GCs are largely excluded from the medial cerebellum (Swanson and Goldowitz, 2011). Now we also find that medially located $\mathrm{Tbr}^{+} \mathrm{CN}$ neurons are missing in the Sey mutant while the Irx $3^{+}$VZ-derived lateral $\mathrm{CN}$ populations are unaffected. In a similar manner, UBCs are largely absent from the Sey cerebellum with the exception of some Tbr2 $2^{+}$cells at the lateral cerebellar RL. These results suggest that there is a requirement of Pax6 function, direct or indirect, for the successful placement of cells in the medial cerebellum. The phenotypes could be due to a failure in the acquisition of a medial subtype identity or a failure in cell migration. In either case, it is now clear that novel functions of Pax6 in each of the glutamatergic neurons is both cell-type and spatially specific.

Pax6 and the molecular underpinnings of cerebellar development

RL precursors express Pax6 and Atoh1 (Yeung et al., 2014). The knock-out of Atoh1 results in the loss of Pax6 expression and eliminates all cerebellar glutamatergic neurons (Machold and Fishell, 2005; Englund et al., 2006; Fink et al., 2006). In contrast, our present work shows that the Pax6 knock-out has no effect on the generation of Atoh1-expressing RL progenitors and eliminates only the $\mathrm{CN}$ neurons and medial UBCs. Thus, the extreme phenotype of the Atoh1-null cerebellum would place Atoh1 upstream of Pax6. In this model (Fig. 10), Atoh1 is necessary for the cell-fate specification of all RL-derived precursors (Yamada et al., 2014). In this study, we find that Pax6 regulates GC survival and proliferation. Furthermore, the present work illuminates the key function Pax6 plays in the development of CN neurons and UBCs. In glutamatergic $\mathrm{CN}$ neuron development, Pax6 is 
upstream of Tbr1 and Tbr2. In the Pax6-null cerebellum there is a complete loss of $\mathrm{Tbrl}^{+} \mathrm{CN}$ neurons, while the Tbr1-knock-out only results in disorganized $\mathrm{CN}$ neurons without cell loss (Fink et al., 2006). Similarly, the Tbr 2 conditional knock-out has no apparent effect on $\mathrm{CN}$ neurons (R. Hevner, personal communication). For UBCs, Pax6 is similarly upstream of Tbr2, as illustrated by the conditional Tbr2-knock-out, which only demonstrates a mild migration defect (R. Hevner, personal communication) compared with the loss of the majority of UBCs in the Sey cerebellum.

\section{Pax6 and the RL-lineage progenitor pool}

The Sey-mutant RL progenitor pool, as manifested by BrdU incorporation, is dramatically reduced and this reduction is particularly evident by late embryogenesis. This finding suggests that Pax6 has a role in regulating the RL progenitor pool (Fig. 10). In fact, earlier work found that Atoh $1^{+}$cells rapidly emigrate from the RL and withdraw from the RL progenitor pool (Machold and Fishell, 2005). Based on our recent analysis of compartmentation in the RL, we speculated that another population of cells (those originating from the interior face of the $\mathrm{RL}$; Wls ${ }^{+} / \mathrm{Pax}{ }^{+}$cells) served to replenish the RL progenitor pool (Yeung et al., 2014). With Pax6 absent, a depletion of the neural progenitor pool has been described in the development of retina and cortex, as a result of precocious cell-cycle exit (Farhy et al., 2013) or shorter cell-cycle length (EstivillTorrus et al., 2002). Interestingly from our CbGRiTS database (cbgrits.org), we find that the transcriptional levels of cyclins $\mathrm{B} 1 / 2$, which promote cell-cycle progression, and p57 (or Cdkn1c), which induce cell-cycle exit, are elevated in the Sey cerebellum, suggesting that both mechanisms may be perturbed in the cells of the RL progenitor pool. Further investigation in cell-cycle dynamics will elucidate the Pax6-dependent regulation in the RL progenitor pool.

This work reveals the novel and essential functions of Pax6 in neurogenesis of glutamatergic CN neurons and UBCs and, together with the revised Pax6 function in GC development, recognizes a more central role of Pax6 in generating the RL lineages. Our work brings to light the multivalent role of Pax6 in cerebellar development, which has commonalities to the role of Pax6 in the genesis of the eye and cortex. This new knowledge enhances our understanding of the molecules underpinning cerebellar development and, more importantly, the requirement of Pax6 in neurogenesis.

\section{References}

Arner E, Daub CO, Vitting-Seerup K, Andersson R, Lilje B, Drabløs F, Lennartsson A, Rönnerblad M, Hrydziuszko O, Vitezic M, Freeman TC, Alhendi AM, Arner P, Axton R, Baillie JK, Beckhouse A, Bodega B, Briggs J, Brombacher F, Davis M et al. (2015) Transcribed enhancers lead waves of coordinated transcription in transitioning mammalian cells. Science 347:1010-1014. CrossRef Medline

Chizhikov VV, Lindgren AG, Currle DS, Rose MF, Monuki ES, Millen KJ (2006) The roof plate regulates cerebellar cell-type specification and proliferation. Development 133:2793-2804. CrossRef Medline

DiCicco-Bloom E, Friedman WJ, Black IB (1993) NT-3 stimulates sympathetic neuroblast proliferation by promoting precursor survival. Neuron 11:1101-1111. CrossRef Medline

Duggan A, Madathany T, de Castro SC, Gerrelli D, Guddati K, GarcíaAñoveros J (2008) Transient expression of the conserved zinc finger gene INSM1 in progenitors and nascent neurons throughout embryonic and adult neurogenesis. J Comp Neurol 507:1497-1520. CrossRef Medline

Engelkamp D, Rashbass P, Seawright A, van Heyningen V (1999) Role of Pax6 in development of the cerebellar system. Development 126:35853596. Medline
Englund C, Kowalczyk T, Daza RA, Dagan A, Lau C, Rose MF, Hevner RF (2006) Unipolar brush cells of the cerebellum are produced in the rhombic lip and migrate through developing white matter. J Neurosci 26:91849195. CrossRef Medline

Ericson J, Rashbass P, Schedl A, Brenner-Morton S, Kawakami A, van Heyningen V, Jessell TM, Briscoe J (1997) Pax6 controls progenitor cell identity and neuronal fate in response to graded shh signaling. Cell 90: 169-180. CrossRef Medline

Estivill-Torrus G, Pearson H, van Heyningen V, Price DJ, Rashbass P (2002) Pax6 is required to regulate the cell cycle and the rate of progression from symmetrical to asymmetrical division in mammalian cortical progenitors. Development 129:455-466. Medline

Farhy C, Elgart M, Shapira Z, Oron-Karni V, Yaron O, Menuchin Y, Rechavi G, Ashery-Padan R (2013) Pax6 is required for normal cell-cycle exit and the differentiation kinetics of retinal progenitor cells. PLoS One 8:e76489. CrossRef Medline

Fink AJ, Englund C, Daza RA, Pham D, Lau C, Nivison M, Kowalczyk T, Hevner RF (2006) Development of the deep cerebellar nuclei: transcription factors and cell migration from the rhombic lip. J Neurosci 26: 3066-3076. CrossRef Medline

Goldowitz D (1989) The weaver granuloprival phenotype is due to intrinsic action of the mutant locus in granule cells: evidence from homozygous weaver chimeras. Neuron 2:1565-1575. CrossRef Medline

Goldowitz D, Mullen RJ (1982) Granule cell as a site of gene action in the weaver mouse cerebellum: evidence from heterozygous mutant chimeras. J Neurosci 2:1474-1485. Medline

Ha TJ, Swanson DJ, Kirova R, Yeung J, Choi K, Tong Y, Chesler EJ, Goldowitz D (2012) Genome-wide microarray comparison reveals downstream genes of Pax6 in the developing mouse cerebellum. Eur J Neurosci 36: 2888-2898. CrossRef Medline

Ha T, Swanson D, Larouche M, Glenn R, Weeden D, Zhang P, Hamre K, Langston M, Phillips C, Song M, Ouyang Z, Chesler E, Duvvurru S, Yordanova R, Cui Y, Campbell K, Ricker G, Phillips C, Homayouni R, Goldowitz D (2015) CbGRiTS: cerebellar gene regulation in time and space. Dev Biol 397:18-30. CrossRef Medline

Jensen P, Zoghbi HY, Goldowitz D (2002) Dissection of the cellular and molecular events that position cerebellar Purkinje cells: a study of the math1null-mutant mouse. J Neurosci 22:8110-8116. Medline

Jensen SA, Calvert AE, Volpert G, Kouri FM, Hurley LA, Luciano JP, Wu Y, Chalastanis A, Futerman AH, Stegh AH (2014) Bcl2L13 is a ceramide synthase inhibitor in glioblastoma. Proc Natl Acad Sci U S A 111:56825687. CrossRef Medline

Machold R, Fishell G (2005) Math1 is expressed in temporally discrete pools of cerebellar rhombic-lip neural progenitors. Neuron 48:17-24. CrossRef Medline

Maisonpierre PC, Belluscio L, Squinto S, Ip NY, Furth ME, Lindsay RM, Yancopoulos GD (1990) Neurotrophin-3: a neurotrophic factor related to NGF and BDNF. Science 247:1446-1451. CrossRef Medline

Millen KJ, Steshina EY, Iskusnykh IY, Chizhikov VV (2014) Transformation of the cerebellum into more ventral brainstem fates causes cerebellar agenesis in the absence of Ptfla function. Proc Natl Acad Sci U S A 111: E1777-E1786. CrossRef Medline

Morales D, Hatten ME (2006) Molecular markers of neuronal progenitors in the embryonic cerebellar anlage. J Neurosci 26:12226-12236. CrossRef Medline

Nikoletopoulou V, Plachta N, Allen ND, Pinto L, Götz M, Barde YA (2007) Neurotrophin receptor-mediated death of misspecified neurons generated from embryonic stem cells lacking Pax6. Cell Stem Cell 1:529-540. CrossRef Medline

Ninkovic J, Pinto L, Petricca S, Lepier A, Sun J, Rieger MA, Schroeder T, Cvek A, Favor J, Götz M (2010) The transcription factor Pax6 regulates survival of dopaminergic olfactory bulb neurons via crystallin alphaA. Neuron 68:682-694. CrossRef Medline

Quinn JC, Molinek M, Martynoga BS, Zaki PA, Faedo A, Bulfone A, Hevner RF, West JD, Price DJ (2007) Pax6 controls cerebral cortical cell number by regulating exit from the cell cycle and specifies cortical cell identity by a cell autonomous mechanism. Dev Biol 302:50-65. CrossRef Medline

Schmahl W, Knoedlseder M, Favor J, Davidson D (1993) Defects of neuronal migration and the pathogenesis of cortical malformations are associated 
with small eye (sey) in the mouse, a point mutation at the pax-6-locus. Acta Neuropathol 86:126-135. CrossRef Medline

Shen W, Zhu L, Lee SR, Chung SH, Gillies MC (2013) Involvement of NT3 and P75NTR in photoreceptor degeneration following selective muller cell ablation. J Neuroinflammation 10:137. CrossRef Medline

Swanson DJ, Goldowitz D (2011) Experimental sey mouse chimeras reveal the developmental deficiencies of Pax6-null granule cells in the postnatal cerebellum. Dev Biol 351:1-12. CrossRef Medline

Swanson DJ, Tong Y, Goldowitz D (2005) Disruption of cerebellar granule cell development in the Pax6 mutant, sey mouse. Brain Res Dev Brain Res 160:176-193. CrossRef Medline

Toresson H, Potter SS, Campbell K (2000) Genetic control of dorsal-ventral identity in the telencephalon: opposing roles for Pax6 and Gsh2. Development 127:4361-4371. Medline

Walther C, Gruss P (1991) Pax-6, a murine paired box gene, is expressed in the developing CNS. Development 113:1435-1449. Medline

Yamada M, Seto Y, Taya S, Owa T, Inoue YU, Inoue T, Kawaguchi Y, Nabeshima Y, Hoshino M (2014) Specification of spatial identities of cerebellar neuron progenitors by Ptfla and Atoh 1 for proper production of GABAergic and glutamatergic neurons. J Neurosci 34:4786-4800. CrossRef Medline

Yeung J, Ha TJ, Swanson DJ, Choi K, Tong Y, Goldowitz D (2014) Wls provides a new compartmental view of the rhombic lip in mouse cerebellar development. J Neurosci 34:12527-12537. CrossRef Medline 